7. Child Lang. 33 (2006), 223-246. (C) 2006 Cambridge University Press doi:I0.1017/So305000906007422 Printed in the United Kingdom

\title{
Object agreement and specificity in early Swahili*
}

\author{
KAMIL UD DEEN \\ University of Hawaii at Manoa, USA \\ (Received I9 April 2004. Revised 28 May 2005)
}

\begin{abstract}
Schaeffer $(\mathrm{I} 997,2000)$ argues that children lack knowledge of specificity because Dutch children omit determiners and fail to scramble pronouns. Avrutin \& Brun (200I), however, find that Russian children place arguments correctly according to whether they are specific or non-specific. This paper investigates object agreement and specificity in early Swahili. Object agreement in Swahili is obligatory when the object is specific, but is prohibited when the object is non-specific. Analysis of naturalistic data from four Swahili-speaking children $(\mathrm{I} ; 8-3 ; 2)$ reveals that children overwhelmingly provide object agreement in obligatory contexts (when the object is a personal name, is topicalized, or refers to first/second person). The supply of object agreement cannot be due to a general strategy of overusing agreement, since object agreement does not occur in prohibited contexts such as intransitive clauses. I conclude that object agreement and knowledge of specificity are acquired by Swahili children before the age of two years.
\end{abstract}

\section{INTRODUCTION}

The acquisition of abstract categories of language such as tense, aspect and agreement (among others) has commanded much of the attention of the field of language acquisition for many decades now. Inflectional elements are of particular interest because they constitute the grammatical glue in a sentence - they bind the nouns and verbs together into coherent sentences. It has been found that young children systematically omit these inflectional elements for an extended period of time. Children in the so-called TELEGRAPHIC SPEECH STAGE (Brown, I973) omit inflectional elements such as

[*] My deepest thanks to Ann Peters for extensive comments on earlier versions of this paper, as well as William O'Grady, the audiences of the Boston University Conference on Language Development and the Conference on Generative Approaches to Language Acquisition in Utrecht in 2003 . Thanks also to Al-Amin Kimathi for help with the data collection, coding and analysis. Address for correspondence: Kamil Ud Deen, Department of Linguistics, I 890 East-West Rd \#559, Honolulu HI 96822 , USA. 
determiners, agreement markers, tense markers, aspect markers, copulas, auxiliary verbs, possessive markers, case markers, etc. This stage of language acquisition begins in the late one-word stage and often continues beyond age four. Thus it appears the elements of language that represent the abstract, functional properties of language are particularly problematic for young children to acquire.

In this paper I investigate the acquisition of one such abstract property of language: nominal specificity. In some languages a noun that refers to a known, specific entity (see below for more on the definition of specificity) is morphologically marked by, for example, an affix. In other languages there is no overt marker of specificity, but other effects of specificity are manifested in the syntax. For example, in Dutch, nouns move leftward when specific (this movement is known as scrambling) but not when they are non-specific. A second example of a syntactic effect of specificity can be seen in Russian, where a specific noun occurs preverbally irrespective of whether it is the subject or object, while a non-specific noun occurs postverbally. We shall return to these Dutch and Russian facts later in this paper.

So at what age do children exhibit this knowledge of specificity? Various authors have made contrasting claims regarding specificity in child language. For example, Schaeffer (2000), based on evidence from child Dutch in which children fail to scramble in obligatory contexts, claims that the nominal feature SPECIFICITY is optionally underspecified in child grammar (on par with the underspecification of temporal specificity, as proposed by Hyams, 1996). Avrutin \& Brun (2001), on the other hand, show that Russian children appropriately place arguments either preverbally or postverbally according to their specificity, thus showing full knowledge of specificity at a very early age. They argue that any errors arise because of unadult-like pragmatic knowledge of what constitutes a specific referent.

The question of whether young children have knowledge of specificity is thus disputed. In this paper I investigate the acquisition of object agreement and specificity in Swahili, a Bantu language spoken in east and central Africa. ${ }^{1}$ I show that children reliably use object agreement (which is dependent on specificity in ways that will be made clear below) in contexts in which object agreement is obligatory. These facts suggest two

[I] As noted by an anonymous reviewer, the language is referred to either as Swahili or KiSwahili. The former is the name of the language in English, while the latter is the name of the language in Swahili itself ( $K i$ - being the noun class prefix for languages). Because this paper is written in English, I adopt the convention of using the English word for the language-Swahili. Additionally, it should be noted that the dialect of investigation is that of Nairobi and the surrounding area. This dialect differs from standard varieties of Swahili in significant ways, but few of these differences have any impact on the data or analyses presented in this paper. See Deen (2005) for details. 
things: (i) Swahili children acquire object agreement fairly early, and (ii) Swahili children (like their Russian counterparts) show early knowledge of specificity.

To date there have been no studies that focus exclusively on the acquisition of object agreement in Swahili or any other Bantu language. However, most studies that look at the acquisition of functional categories in Bantu (e.g. Deen, 2002 a, b, 2003, 2005 for Swahili; Demuth, I 984, I 988 , I $992 a, b$ for Sesotho; Suzman, I982, I99I for Zulu; Kunene, I979 for Siswati; Chimombo \& Mtenje, I989 for Chichewa; Tsonope, I987 for Setswana) mention object agreement to some degree. For example, Demuth (I $992 a, 599-600)$, in her thorough description of the acquisition of Sesotho, describes the acquisition of object agreement as taking roughly the same path as the acquisition of subject agreement: it is initially omitted, and then occurs in the form of 'shadow vowels' (non-distinct vowels such as schwa that precede the verb in place of agreement), followed by the appropriate use of object agreement. Thus while object agreement is acquired fairly early in other Bantu languages, there are clear stages in which it is omitted, as well as clear developmental stages. If object agreement is omitted in child Swahili (as appears to be the case in child Sesotho), it raises the question of whether the omission of object agreement is related to an absence of knowledge of sPECIFICITY, or to some other factor.

The remainder of this paper is organized as follows. In the next section I discuss the notion of specificity and review the studies on the acquisition of specificity: Schaeffer's (2000) investigation of Dutch scrambling and Avrutin \& Brun's (200I) study on the acquisition of argument placement in Russian. I next present the relevant portions of adult Swahili morphosyntax, showing the agreement patterns and the structure of the verbal complex. I then describe the methodology and data employed in this study, followed by the results and discussion.

\section{The acquisition of specificity}

There is no clear consensus on a definition of nominal specificity in the literature. The definition that I employ is the following (see Karimi, I 999; von Heusinger, 2002): ${ }^{2}$

(I) a. Referent is known in the discourse

b. It may be either definite or indefinite

c. An indefinite specific NP can either denote inclusion or is singled out in discourse (e.g. by a relative clause)

[2] See also Fodor \& Sag (I982), Hornstein (1984) and Enç (I99I) for more syntactic treatments of specificity. 
How is specificity encoded in the languages of the world? Let us begin with English, which has no overt morphological marking for specificity. A common way to identify specific NPs in English is by the use of adjectives such as certain, or specific, or particular (Enç, I99I), as in (2):

(2) a. Kitty plays with a teddy bear.

Non-specific

b. Kitty plays with a particular teddy bear. Specific

The notion of SPECIFICITY must be differentiated from DEFINITENEss, which can be defined as follows: 'a definite NP picks out a unique and familiar entity' (see Heim, I982; Abbott, 2005, amongst others for more detailed discussion of definiteness). A good context that differentiates these two notions is non-specific definites, as in example (3):

(3) The telephone was the greatest invention of the igth century.

Here, the telephone is a unique and familiar object (and hence it is marked with the definite determiner), but it is not specific. This can be seen clearly if a specificity-inducing adjective such as particular is inserted, as in (4):

(4) The particular telephone was the greatest invention of the I9th century.

The use of the adjective particular results in the unusual reading that a single, specific telephone (e.g. the one first produced by Alexander Bell) was the greatest invention of the I 9 th century. This illustrates the difference between specificity and definiteness: the former picks out a particular entity that the speaker has in mind, while the latter picks out any known or familiar entity, whether specific or not.

Languages that mark specificity are generally thought to do so in two ways: either through an overt morpheme or through some syntactic process of movement of an element out of the verb phrase (or both, see Bhatt \& Anagnostopoulou, I996). For example, (5a, from Karimi, I999) shows that a specific object in Persian is marked with the specificity marker $r o$ or its dialectal variant $r \hat{a}$, while a non-specific object $(5 \mathrm{~b})$ is unmarked.

(5) a. Kimea un ketâb ro barâ man xarid Kimea that book râ for me bought

'Kimea bought that book for me.'

b. Kimea barâ man (ye) ketâb xarid

Kimea for me (a) book bought

'Kimea bought (a) book for me.' 
Similarly, in Boruca (a Chibchan language spoken in Costa Rica), nouns marked with $k i$ are obligatorily interpreted as specific (6a), while nouns without $k i$ are non-specific (6b, examples taken from Quesada, 2000):

(6) a. At ki ya' do'-ra e'tse ramróhk tíshibi' ki ki e’de Isg subj refl marry-pres one woman Terraba spec with 'I will marry a woman from Terraba (whom I know).'

b. At ki ya' do'-ra e’tse ramróhk tíshibi' e'de isg subj refl marry-pres one woman Terraba with

'I will marry a woman from Terraba (whom I do not know).'

While specificity is marked morphologically in languages such as Persian and Boruca, effects of specificity may appear in the syntax as well. For example, in the Persian sentences in (5), the position of the direct object noun phrase ketâb changes depending on whether it is specific or not - when the object is specific (5a) it occurs before the benefactive barâ man, but when the object is non-specific, it occurs after the benefactive. Similar syntactic effects are attested in Dutch and Russian, to which we now turn.

\section{Specificity in adult and child Dutch (Schaeffer, 2000)}

In adult Dutch, nouns that are specific may scramble (defined as leftward movement of a noun or a verb), while non-specific nouns may not scramble. $^{3}$ Because pronouns are inherently specific, they obligatorily scramble : ${ }^{4}$

(7) a. *dat Saskia waarschijnlijk niet het gelezen heeft that Saskia probably not it read has

b. *dat Saskia waarschijnlijk het niet gelezen heeft that Saskia probably it not read has

c. dat Saskia het waarschijnlijk niet gelezen heeft that Saskia it probably not read has

[3] The term 'scrambling' here refers specifically to the Dutch facts described in the text, and is generally understood to mean movement of an element leftward (although it may also be rightward movement), often across adverbs and/or negation (as evidence of whether movement has occurred or not). It should be noted that there are several kinds of scrambling (e.g. the kind found in Japanese), which are analysed in different ways. I make no commitment to any theoretical analysis of scrambling, nor do I wish to imply that Dutch scrambling and other kinds of scrambling are a unified phenomenon.

[4] In adult Dutch, scrambling of pronouns is obligatory, as described in the text. The case of non-pronominal specific objects is more tricky: specific, non-pronominal objects OPTIONALLY scramble. Crucially, however, non-specific objects never scramble, showing that specificity is an important factor in the licensing of scrambling. This suggests that specificity does not directly determine scrambling, but rather is one factor amongst several. I limit my discussion here to pronominal objects because it is the only case in which scrambling is obligatory, although as I suggest in the conclusion, this quirk of Dutch may indeed prove to be important. 
DEEN

TAB LE I. Scrambled and unscrambled pronouns in child Dutch

\begin{tabular}{cccccc}
\hline & \multicolumn{2}{c}{ Niek } & & \multicolumn{2}{c}{ Laura } \\
\cline { 2 - 3 } \cline { 5 - 6 } \cline { 5 - 6 } & Scrambled & Unscrambled & & Scrambled & Unscrambled \\
\hline Stage I & $71 \%$ & $29 \%$ & & $30 \%$ & $70 \%$ \\
Stage II & $78 \%$ & $22 \%$ & & $88 \%$ & $12 \%$ \\
\hline
\end{tabular}

Niek Stage I : $2 ; 7-3 ; 5$, Stage II : 3;6-3; I I Laura Stage I : I ; I0-3;4, Stage II : 3; 5-5;4.

Schaeffer (2000) investigates scrambling and determiners in two Dutch children aged I ; I0-5; 4. Table I (adapted from Schaeffer, 2000) shows the rate of scrambled pronouns in the speech of two Dutch speaking children, Niek and Laura. The results are divided into two developmental stages (the point at which the majority of pronouns were scrambled marks the beginning of stage II).

Table I shows that in Stage I, Niek fails to scramble pronouns $29 \%$ of the time, while Laura fails to scramble pronouns $70 \%$ of the time. In stage II, while Laura does not show full mastery of pronoun scrambling, she has improved considerably. This shows that in early Dutch (unlike adult Dutch) children do not always scramble pronouns. Schaeffer takes this as evidence that specificity in child Dutch may be optionally underspecified. As additional evidence, Schaeffer points to the omission of determiners in obligatory contexts. While determiners in Dutch do not mark specificity per se, Schaeffer considers definiteness to largely overlap with specificity. She finds that at early stages determiners are omitted at extremely high rates, as shown in Table 2.

As with scrambling, Laura shows improvement in stage II. Schaeffer argues that both determiner omission as well as the optionality of scrambling occur because of the optional underspecification of the feature SPECIFICITY. ${ }^{5}$ If this is correct, it raises the question of whether effects of the lack of knowledge of specificity are attested in other languages. The only other study of the acquisition of specificity that I am aware of is

[5] Schaeffer argues that competence in interpreting nominal specificity develops as pragmatic principles develop. She argues that, as in the case of principle B of the binding theory, there are two options for the interpretation of nominals. The first is through syntax in which a specificity operator binds the D variable, resulting in a specific interpretation. The second is through discourse, where the operator and D pick out the same (specific) referent in discourse. The second option is ruled out in adult Dutch through a pragmatic principle (akin to Reinhart's (1983) Principle I of the binding theory) which disallows the discourse option if a syntactic option is available. Schaeffer argues that this pragmatic principle has not developed in young Dutch children. The details of this are not important here. What is of concern is that Dutch children show evidence that specificity is problematic. 
OBJECT AGREEMENT AND SPECIFICITY IN EARLY SWAHILI

TAB LE 2. Nouns with and without determiners in child Dutch

\begin{tabular}{cccccc}
\hline & \multicolumn{2}{c}{ Niek } & & \multicolumn{2}{c}{ Laura } \\
\cline { 2 - 3 } \cline { 5 - 6 } \cline { 5 - 6 } & + Determiner & - Determiner & & + Determiner & - Determiner \\
\hline Stage I & $6 \%$ & $94 \%$ & & $31 \%$ & $69 \%$ \\
Stage II & $44 \%$ & $56 \%$ & & $86 \%$ & I $4 \%$ \\
\hline
\end{tabular}

Niek Stage I : $2 ; 7-3 ; 5$, Stage II : 3;6-3; I I Laura Stage I : I ; I0-3;4, Stage II : 3; 5-5;4.

Avrutin \& Brun (200I), who investigate the acquisition of specificity in Russian, to which I now turn.

Avrutin छे Brun (200I)

In Russian, specificity plays a role in argument placement. In adult Russian, all preverbal arguments (irrespective of whether they are the subject or the object) are interpreted as specific and all postverbal arguments are interpreted as non-specific. ${ }^{6}$ The examples in (8) are taken from Avrutin \& Brun (200I, p. 7I):

(8) a.
a. Mal'čik
činit
igrušku
(the) boy-NOM is-fixing
'The boy is fixing a toy.'
b. Igrušku
činit
mal'čik
(the) toy-ACC is-fixing (a/some) boy-NOM
'A boy is fixing the toy.'

If it is true that children lack knowledge of specificity, the prediction for Russian is clear: children should misplace arguments. Avrutin \& Brun tested this hypothesis using naturalistic data from four Russian speaking children aged $\mathrm{I} ; 7$ to $2 ; 3$. The surrounding context (including parental speech) and the presence of certain markers denoting specificity and non-specificity were used to determine whether the intended interpretation was specific or non-specific. The results of their analysis are presented in Table 3 .

Considering subjects first (shown on the left side of Table 3), of all the specific subjects, 90\% were correctly preverbal, and of all the non-specific subjects, $32 \cdot 2 \%$ were incorrectly preverbal. Now considering objects (shown on the right side of Table 3 ), of all the specific objects, $89 \cdot 4 \%$ correctly occurred preverbally, and of all the non-specific objects, $9 \cdot 7 \%$ occurred

[6] It is noteworthy that both the Dutch and Russian effects described here involve leftward movement of the specific object. A discussion of this is beyond the scope of this article, although see Diesing (1992), Mahajan (1992), Bhatt \& Anagnostopoulou (I996), Karimi (2003) among others. Specificity does however have other effects, such as the one that is the topic of this paper: the licensing of object agreement. 
DEEN

TAB LE 3. Distribution and interpretation of subjects and objects in child Russian (Avrutin E० Brun, 200I)

\begin{tabular}{|c|c|c|c|c|c|c|c|c|}
\hline & \multicolumn{4}{|c|}{ Subjects } & \multicolumn{4}{|c|}{ Objects } \\
\hline & \multicolumn{2}{|c|}{ Preverbal } & \multicolumn{2}{|c|}{ Postverbal } & \multicolumn{2}{|c|}{ Preverbal } & \multicolumn{2}{|c|}{ Postverbal } \\
\hline & $n$ & $\%$ & $n$ & $\%$ & $n$ & $\%$ & $n$ & $\%$ \\
\hline Specific & $34 \mathrm{I}$ & $90 \cdot 0$ & 38 & $10 \cdot 0$ & 245 & $89 \cdot 4$ & 29 & $10 \cdot 6$ \\
\hline Non-specific & 49 & $32 \cdot 2$ & 103 & $67 \cdot 8$ & I 8 & $9 \cdot 7$ & I 68 & $90 \cdot 3$ \\
\hline
\end{tabular}

incorrectly preverbally. Putting aside the elevated rate of preverbal nonspecific subjects $(32 \cdot 2 \%)$ for the time being, the other three results show that Russian children have knowledge of specificity since the error rate in all cases is approximately $10 \%$ or less. Avrutin \& Brun attribute the elevated rate of non-specific preverbal subjects $(32 \cdot 2 \%)$ to a topicality effect, arguing that children mistakenly assume that subjects are specific because they are often weak topics. Because topics are specific, children are prone to misplacing subjects. Thus this amounts not to a syntactic error, but a pragmatic one in that children fail to recognize that the subject is not an entity known to the interlocutors.

The conclusion that Avrutin \& Brun draw is that Russian children, unlike their Dutch counterparts, show knowledge of specificity from as early as $1 ; 7$. The current study aims to resolve these conflicting results by presenting evidence of the acquisition of specificity and object agreement in early Swahili. I will first present some facts about Swahili morphosyntax that show why Swahili is a good language to investigate the acquisition of specificity.

\section{Swahili verbal complex}

Swahili is a Subject-Verb-Object language (see 9 below) with the verb root embedded within a verbal complex that minimally contains subject agreement (SA), tense, the root and a final mood vowel. SA marks number and person (see Table 4 ), but case is not marked morphologically. ${ }^{7}$ Table 4 also provides a non-exhaustive list of some tense/aspect markers.

[7] In all Swahili examples, $\mathrm{SA}=$ Subject Agreement, $\mathrm{OA}=$ Object Agreement, $\mathrm{IND}=$ Indicative $\operatorname{mood}, \mathrm{SUBJ}=$ Subjunctive $\operatorname{mood}$, past $=$ past tense, pres $=$ present tense, fut $=$ future tense. Numbers preceding a noun indicate noun class, and person and number features of agreement are indicated in subscript on the agreement marker. Thus $\mathrm{SA}_{1 \mathrm{~s}}$ indicates first person, singular subject agreement. The only exceptions are examples (I I) and (I 8 ) in which the subscript indicates inanimacy. I have not included noun class information on the agreement glosses because (with the exception of II and I8) all examples are of agreement within noun classes $I$ and 2, and thus person and number features are the most relevant. 


\begin{tabular}{lcccl}
\hline & $\begin{array}{c}\text { Subject } \\
\text { agreement }\end{array}$ & $\begin{array}{c}\text { Object } \\
\text { agreement }\end{array}$ & Tense/aspect & \multicolumn{1}{c}{ Meaning } \\
\hline Ist singular & ni- & - ni- & - li- & past \\
2nd singular & u- & $-k u-$ & - na- & Pres. on-going/habitual \\
3rd singular & a- & - m- & - ta- & future \\
Ist plural & tu- & - tu- & - ka- & Narrative \\
2nd plural & mu- & - mu- & - me- & Pres. perfect \\
3rd plural & wa- & - wa- & -sha- & Pres. perfect completive \\
\hline
\end{tabular}

\begin{tabular}{|c|c|c|c|}
\hline \multirow{3}{*}{ (9) } & Subject & Verbal complex & Object \\
\hline & Juma & $a-n a-m-$ pend $-a$ & Mariam \\
\hline & $\begin{array}{l}\text { Juma } \\
\text { 'Juma li }\end{array}$ & $\begin{array}{l}\mathrm{SA}_{3 \mathrm{~s}}-\mathrm{PRES}-\mathrm{OA}_{3 \mathrm{~s}} \mathrm{~s} \text {-like - IND } \\
\text { ikes Mariam.' }\end{array}$ & Mariam \\
\hline
\end{tabular}

Object Agreement (OA, also shown in Table 4), like SA, marks person and number. However, OA is not obligatory in every transitive verb, but is subject to the SPECIFICITY CONDITION:

The Specificity Condition: If the object is specific, OA is obligatory (Ioa), and if the object is non-specific, OA is obligatorily absent (Iob; Ashton, I947).
(Iо) a. Juma a-li-mw-on-a $\mathrm{m}-\mathrm{tu} \quad[+\mathrm{OA}] \rightarrow$ Obligatorily Juma $\quad \mathrm{SA}_{3 \mathrm{~s}}-$ past $-\mathrm{OA}_{3 \mathrm{~s}}-\mathrm{see}-\mathrm{IND}$ I-person Specific 'Juma saw the person / *a person.'
b. Juma a-li-on-a $m-$ tu Juma $\quad \mathrm{SA}_{3 \mathrm{~s}}-$ past-see-IND $\mathrm{I}$-person 'Juma saw a person / *the person.'
$[-\mathrm{OA}] \rightarrow$ Obligatorily Non-specific

As mentioned in the previous section, it is important to distinguish between specificity and Definiteness. I assume here that OA in Swahili marks specificity, and not definiteness (see also Carstens, I99I). This is best shown in contexts in which definiteness and specificity are dissociated, because the Specificity Condition predicts that OA will occur in specific contexts but not in definite contexts. As we saw earlier, a good situation in which to investigate this is non-specific definites. It is not easy (for discourse reasons) to construct non-specific definite contexts for object position, hence the slight awkwardness of example (I I). In response to the question 'What did you study for your $\mathrm{PhD}$ in history?' an appropriate answer such as (I Ia) requires that OA be absent. The intended interpretation of (IIa) is that the person studied the history of the invention 
known as 'The Telephone.' This therefore indicates a non-specific but definite NP (either the telephone as an invention, or the history of the telephone).

( I I) a. ni-li-som - a simu $\mathrm{SA}_{1 \mathrm{~s}}$ - past - study - IND telephone $[-\mathrm{OA}]$ 'I studied The Telephone.'

[+Definite $],[-$ Specific $]$

b. $n i-l i-i-s o m-a \operatorname{simu}$

$\mathrm{SA}_{1 \mathrm{~s}}-$ past $-\mathrm{OA}_{\text {inanim }}-$ study $-\mathrm{IND}$ telephone [+Definite], [+ Specific]

'I studied (that particular) telephone.'

A specific response is given in ( $\mathrm{I}$ Ib), resulting in the unusual interpretation in which the person studied the history of a particular telephone, e.g. from the time it was manufactured in a factory through the present time. This shows that OA in Swahili is NOT a marker of definiteness, but a marker of specificity.

An anonymous reviewer pointed out that there have been occasional claims in the literature that OA is obligatory with the 'human' noun classes I and 2 (see Seidl \& Dimitriadis, 1997 for discussion of this point). This claim yields the prediction that whenever the object belongs to noun class I/2 (see the next paragraph for an explanation of these noun classes), OA always occurs. This prediction is probably statistically correct, but for discourse reasons and not because of any grammatical restriction on OA with respect to noun classes $\mathrm{I} / 2$.

Noun classes in Bantu are a morphological system of classifying nouns. They are very much like gender systems of European languages, only in Bantu there are often more than ten noun classes, as opposed to the two or three gender classes in European languages. Additionally, there are often (but not always) semantic criteria that help determine noun class membership, unlike European gender systems, which are essentially arbitrary. In Swahili (as in most Bantu languages), noun class marking occurs as a prefix on the noun (examples 12 and I3). Noun classes $1 / 2$ are reserved primarily for human referents, with noun class $\mathrm{I}$ the singular counterpart of noun class 2 .
(I2) a. $\mathrm{M}-\mathrm{tu}$
b. $\mathrm{Wa}-\mathrm{tu}$
I - person
'person'
2-person
'people'
c. M-levi
I - drunkard
'Drunkard'
d. Wa-levi
2-drunkard
'Drunkards'

Returning to an explanation of why OA would seem obligatory with objects of noun classes $\mathrm{I} / 2$, it is well known that old information usually 
occurs in object position. Therefore in the case of objects that are human (as in noun classes I and 2), it is very likely that the human referent has already been introduced into the discourse, and is thus 'known' to the interlocutors. A known human referent is most likely specific, yielding the association of noun class I/2 with OA. However, as evidence of the fact that this is not a grammatical restriction, the examples in (I3) show the difference between a specific object of noun class I and a non-specific object of noun class $\mathbf{I}$ (both acceptable):

$\begin{array}{lll}\text { (I3) a. Jana } & \mathrm{ni}-\mathrm{li}-\mathrm{on}-\mathrm{a} & \mathrm{m} \text {-levi } \quad \text { [-specific, noun class I] } \\ \text { yesterday } & \mathrm{SA}_{1 \mathrm{~s}}-\text { past-see- IND } & \mathrm{I} \text {-drunkard }\end{array}$ 'Yesterday I saw (some) drunkard.'

b. Jana ni-li-mw-on-a m-levi [+specific, noun class $\mathrm{I}]$ yesterday $\mathrm{SA}_{1 \mathrm{~s}}-$ past- $\mathrm{OA}_{3 \mathrm{~s}}-$ see-IND $\mathrm{I}$-drunkard

'Yesterday I saw (that) drunkard.'

I therefore conclude that the presence of OA on the verb is dependent on nominal specificity, making Swahili a good language to investigate children's knowledge of specificity. If Swahili children omit OA when the object is specific, this may be evidence that knowledge of specificity is absent. ${ }^{8}$ However, if Swahili children (i) reliably provide OA in obligatory contexts and (ii) do not provide OA in prohibited contexts, we can conclude that Swahili children have adultlike knowledge of specificity.

\section{METHOD}

\section{Subjects}

The data come from biweekly audio recordings of naturalistic speech in the homes of four children in Nairobi, Kenya. The data were audio recorded and transcribed using CHAT format. The ages, number of recordings, MLUs and Verb ratios (the ratio of verbs to total utterances, Valian, I99 I) are given in Table 5 .

Each of the children was assigned to a particular stage or stages according to 3 measures of grammatical development: MLU, verbs per utterance (Valian, I99I) and proportion of filler syllables/protosyntactic devices (Bottari, Cipriani \& Chilosi, I993/ı994; Peters, 200I). I then pooled the data from each stage, according to the cut-off points shown in Table 6.

According to these measures, the children represent 4 developmental stages with one of the children (Mus) passing through more than one

[8] Of course, the omission of OA may also be due to some other factor unrelated to specificity. As we will see shortly, Swahili children do not omit OA in obligatory context, rendering this point moot. 
DEEN

TABLE 5. Subject information

\begin{tabular}{lcccc}
\hline Child & Haw & Mus & Fau & Has \\
\hline Age range & $2 ; 2-2 ; 6$ & $2 ; 0-2 ; \mathrm{II}$ & $\mathrm{I} ; 8-2 ; 2$ & $2 ; \mathrm{I} 0-3 ; \mathrm{I}$ \\
\# of recordings & 7 & 23 & $\mathrm{IO}$ & 5 \\
MLU & $\mathrm{I} \cdot 54^{-2} \cdot 46$ & $\mathrm{I} \cdot 52-3.57$ & $2 \cdot 97-3.93$ & $3.15-4.23$ \\
V Ratio & $0 \cdot 07-.14$ & $0.05-.17$ & $0.20-.36$ & $0.30-.40$ \\
\hline
\end{tabular}

TA B LE 6. Cut-off points for determining stages in the Swahili corpora

\begin{tabular}{cccc}
\hline & MLU & Verbs/utterance & $\%$ filler syllables \\
\hline Stage I & $<2.5$ & $<0.15$ & $>25 \%$ \\
Stage 2 & $2.5-3.0$ & $0.15-.20$ & I $5-24 \%$ \\
Stage 3 & $3.0-3.5$ & $0.20-.25$ & $5-14 \%$ \\
Stage 4 & $>3.5$ & $>0.25$ & $<5 \%$ \\
\hline
\end{tabular}

stage during the time of the study (see Deen 2002a, 2005 for further details).

\section{METHOD}

All recordings were made in the homes of the children with one caregiver present. The investigator was also present, taking contextual notes to supplement the audio recordings. All recordings were transcribed by the investigator as soon after the recording session as possible. All transcripts were then checked by a native speaker assistant for accuracy. Additionally, morphological coding was inserted into the transcripts at the time of transcribing. Filler syllables were given special codes to distinguish them from well-formed morphemes. The accuracy of the coding was then checked in the following manner. A random section of each transcript containing at least 100 morphological codes was selected and re-coded by an assistant. If any one transcript failed to meet an inter-coder reliability criterion of $98 \%$ (which happened once), that transcript was re-coded in its entirety by the investigator and the submitted to the same verification method. All analyses of the data were conducted using CLAN programs (MacWhinney, 2000).

\section{RESULTS}

\section{Acquisition of $O A$}

As a first analysis of the acquisition of OA, Table 7 shows the overall number of tokens of OA in the Swahili corpora, by stage. The proportion of 
TABLE 7. OA across the four stages

\begin{tabular}{lllll}
\hline & Stage I & Stage 2 & Stage 3 & Stage 4 \\
\hline Tokens of OA & $38(6 \%)$ & $27(5 \%)$ & I02 $($ I6\%) & $66($ I3\%) \\
Total verbs & 639 & 535 & $6_{3} 8$ & 5 I9 \\
\hline
\end{tabular}

verbal utterances marked with $\mathrm{OA}$ in this data ranges from $5 \%$ (stage 2) to I6\% (stage 3). These figures are presented simply to provide a sense of how often OA occurs in the speech of children. Contrasts in person in OA occur in stage I (Ist versus 2nd person, see (I4) below), and there are no errors whatsoever in person agreement even in stage $\mathbf{I}$.

\begin{tabular}{|c|c|c|c|c|c|c|}
\hline $\begin{array}{l}\text { (I4) } \\
\text { adult: }\end{array}$ & $\begin{array}{ll}\text { a. } & \partial- \\
& \mathrm{a}- \\
& \mathrm{SA}_{3 \mathrm{~s}}- \\
& \text { 'She sl }\end{array}$ & $\begin{array}{l}\text { li- } \\
\text { li- } \\
\text { past- } \\
\text { apped } \mathrm{r}\end{array}$ & $\begin{array}{l}\mathrm{ni}- \\
\mathrm{ni}- \\
\mathrm{OA}_{1 \mathrm{~s}}- \\
\text { ne.' }\end{array}$ & $\begin{array}{l}\text { chap - } \\
\text { chap - } \\
\text { slap - }\end{array}$ & $\begin{array}{c}\mathrm{a} \\
\mathrm{a} \\
\mathrm{IND}\end{array}$ & $\begin{array}{l}\text { Ist person sg OA } \\
\text { (Musi9, age } 2 ; 8.25 \text { ) }\end{array}$ \\
\hline adult: & $\begin{array}{l}\text { b. ni- } \\
\text { ni- } \\
\mathrm{SA}_{1 \mathrm{~s}}- \\
\text { 'I will }\end{array}$ & $\begin{array}{c}\varnothing- \\
\text { ta - } \\
\text { fut - } \\
\text { slap yo }\end{array}$ & $\begin{array}{l}\mathrm{ku}- \\
\mathrm{ku}- \\
\mathrm{OA}_{2 \mathrm{~s}}-\end{array}$ & $\begin{array}{l}\text { tap - } \\
\text { chap - } \\
\text { slap - }\end{array}$ & $\begin{array}{l}\mathrm{a} \\
\mathrm{a} \\
\text { IND }\end{array}$ & $\begin{array}{l}\text { 2nd person sg OA } \\
\text { (Musi } 9 \text {, age } 2 ; 8.25\end{array}$ \\
\hline
\end{tabular}

However, it should be noted that the figures in Table 7 are not very informative because we do not know how many obligatory contexts there are in this data. That is, OA may occur correctly 38 times in stage I, but how often is it omitted in obligatory context? Recall that obligatory context in Swahili is when the object is specific. Without knowing the rate of OA in specific contexts, we cannot answer the question of whether Swahili children have acquired $\mathrm{OA}$, nor whether they obey the Specificity Condition on OA.

\section{Specificity and problems with naturalistic data}

An obligatory context for $\mathrm{OA}$ is difficult to determine in child language because it is not always possible to unambiguously determine a child's intention. For example, if an English speaking child, speaking of a toy that is on the edge of the bed, says $I$ want toy, this would most naturally be interpreted by an adult as $I$ want the toy, I want my toy or $I$ want that toy. However, it could also (conceivably) be interpreted as I want a/any toy. That is, perhaps the child wants any toy without having a particular one in mind, but the adult naturally assumes that the child wants the toy that is present in the room. Despite context strongly suggesting that the child is omitting a definite determiner, possessive pronoun, or a demonstrative, it is impossible to unambiguously determine this without knowing the child's intention. 
Similarly in adult Swahili, example (I 5) can only have a non-specific reading because there is no $\mathrm{OA}$ on the verb. If this sentence is uttered in a context in which it is clear that the referent is already-mentioned and specific, then an adult will consider this ungrammatical. However, we cannot rule out the possibility that the child intends a non-specific reading, i.e. although the referent may be known and specific to the adult, the child may have forgotten that it was already mentioned in the discourse or that the adult has knowledge of the referent in question.

$$
\begin{aligned}
& \text { (i 5) a. Juma a-li-on-a m-tu } \\
& \text { Juma } \mathrm{SA}_{3 \mathrm{~s}} \text {-past-see-IND I-person } \\
& \text { 'Juma saw a person/ *the person.' }
\end{aligned}
$$

Non-specific only

The problem is that most nouns can be both specific and non-specific in Swahili since there are no overt markers of nominal specificity. In order to get around this problem, I focus on three contexts in which the object is obligatorily specific (and thus OA is obligatorily marked): (i) when the object is a personal name, (ii) when the object is topicalized, and (iii) when the object is a first or second person referent.

\section{$O A$ with names}

Objects that are personal names are inherently specific. Thus when the object is a proper name, it is always (unambiguously) specific, and OA is always (without exception) required. ${ }^{9}$ This therefore constitutes an obligatory context for OA.

$$
\begin{aligned}
& \text { (i6) a. ni- li }-\mathrm{mw}-\text { on }- \text { a Mariam jana } \\
& \mathrm{SA}_{1 \mathrm{~s}}-\text { past - } \mathrm{OA}_{3 \mathrm{~s}}-\text { see }- \text { IND Mariam yesterday } \\
& \text { 'I saw Mariam yesterday.' } \\
& \begin{array}{lllll}
\text { b. }{ }^{*} \text { ni }- & \text { li }- & \varnothing-\text { on }- & \text { a } & \text { Mariam jana } \\
\mathrm{SA}_{1 \mathrm{~s}}- & \text { past }- & \varnothing-\mathrm{see}- & \mathrm{IND} & \text { Mariam yesterday }
\end{array}
\end{aligned}
$$

An analysis of the Swahili corpora reveals that there are a total of 963 personal names produced by the children, of which 183 are postverbal (potential preverbal object personal names are included in the analysis of topicalized objects in the next section). Of these $8_{3}$ names, I excluded vocatives and postverbal subjects (all clearly identifiable from context and

[9] It is conceivable that children incorrectly treat proper names as non-specific. However, this would be extremely strange, e.g. I kissed Mary would mean 'I kissed any woman named Mary'. See Bloom (2000) for a review of evidence that children do not make such errors. 
TA В LE 8. OA with personal names and topicalized nouns

\begin{tabular}{lc|ccccr}
\hline & $\begin{array}{c}\text { Clauses with } \\
\text { names as objects }\end{array}$ & Lexical noun & $\begin{array}{c}\text { Topicalized nouns } \\
\text { pronoun }\end{array}$ & Name & Demonstrative & Total \\
\hline +OA & $25(93 \%)$ & 3 & $\mathrm{I}$ & 2 & 4 & 10 \\
- OA & $2(7 \%)$ & 0 & $\circ$ & 0 & 2 & 2 \\
\hline
\end{tabular}

intonation), as well as unclear cases. This left 27 cases of unambiguous object proper names. Of these 27 tokens, 25 (93\%) correctly occurred with OA, while $2(7 \%)$ occurred without OA (see the first column of Table 8 ). The 25 correct occurrences of OA come from all four stages of the corpus, beginning in late stage $\mathrm{I}$. Thus in obligatory contexts, Swahili children omit OA only $7 \%$ of the time. Of these 2 tokens of OA-omission, one occurred in stage $\mathrm{I}$ and the other in stage 3 . This high rate of $\mathrm{OA}$ in this particular context suggests that children do have knowledge of the specificity condition on $\mathrm{OA}$.

\section{$O A$ with topicalized objects}

The second obligatory context for OA involves objects that have been topicalized. Topics are obligatorily specific, and thus obligatorily occur with OA in Swahili.

$$
\begin{aligned}
& \text { a. M-toto, ni-li-mw-on - a Topicalized Obj with OA } \\
& \text { I - child } \quad \mathrm{SA}_{1 \mathrm{~s}}-\text { past }-\mathrm{OA}_{3 \mathrm{~s}}-\text { see-IND } \\
& \text { '*A/The child, I saw (him/her)' } \\
& \text { b. *M-toto, ni-li-Ø-on-a Topicalized Obj without OA } \\
& \text { I - child } \quad \mathrm{SA}_{1 \mathrm{~s}}-\text { past-Ø-see-IND }
\end{aligned}
$$

In order to identify possible topics, I first extracted from the corpora all utterances in which a lexical noun, object pronoun, personal name or demonstrative occurred before a transitive or ditransitive verb. There were a total of 98 preverbal lexical nouns, I preverbal object pronoun, I75 preverbal names, and 48 preverbal demonstratives. Each utterance was then inspected and all topicalized objects were identified using the preceding and following child and adult utterances, as well as contextual notes that were taken by the experimenter at the time the data was recorded. All repetitions, imitations, etc. were discarded. The vast majority of the preverbal nominals were subjects or vocatives, with the remainder being topicalized objects. The results are presented in the right-hand group of columns in Table 8. 
Of the I 2 unambiguous topicalized objects, ro occur with OA. There are 2 cases of objects that have been topicalized but occur without OA. These exceptions are listed below:

$$
\begin{aligned}
& \text { a. na...hiyo } \mathrm{ni}-\varnothing-\text { tow }-\mathrm{e} \\
& \text { na hiyo, ni- i- tow - e } \\
& \text { and that } \mathrm{SA}_{1 \mathrm{~s}}-\mathrm{OA}_{\text {inanim }}-\mathrm{remove}-\mathrm{SUBJ}
\end{aligned}
$$

FAUO3, age I;9. I 4

intended: 'And (perhaps) that, I should remove (it).'

b. hile, si hile ni-li-Ø-som - a

FAUO5, I ; I I.OI

adult: si hile, ni-li-i-som-a

see that $\mathrm{SA}_{1 \mathrm{~s}}-$ past- $\mathrm{OA}_{\text {inanim }}-\mathrm{read}-\mathrm{IND}$

intended: 'See, that, I read (it).'

Note that in both these examples the missing OA marker is [i] and the immediately preceding vowel is also [i] (see the lines marked 'adult' in (I8)). Thus it is possible that these are not cases of OA omission, but rather vowel coalescence or reduction. In adult Swahili these are pronounced with a long vowel, and because these child utterances in (I8) were pronounced with short vowels, I categorized them as missing OA. Such processes are not uncommon in the acquisition of Bantu languages. For example, Demuth (I992a, 606) describes such a process in the production of two consecutive morphemes, the applicative $-e l$ - and the perfect -il-, in which the child combines the two to produce -ets-. A second example of coalescence is shown in Demuth (1994, I24), in which the SA (ke-) and $\mathrm{T}(-a-)$ markers coalesce to form a CV syllable $(t a-)$. The point simply is that the examples in (I8) are unclear and may be considered exceptions or not, depending on one's theoretical preference. My preference is to exclude unclear cases, and so if we put these two aside, ro topicalized objects are left, all of which are marked with OA. This is therefore a second piece of evidence suggesting that Swahili children have knowledge of OA and the Specificity Condition.

\section{$O A$ with first and second person objects}

The third context in which we can reliably expect both specific objects and the corresponding $\mathrm{OA}$ is when the object refers to a first or second person. That is, when the object refers to one of the conversational participants (you or me), a non-specific reading is impossible. Thus if children have knowledge of the Specificity Condition in Swahili, they should reliably produce object agreement when the object refers to a first or second person. For this analysis, all intransitive verbs were excluded and the remaining transitive and ditransitive utterances were inspected. The reference of the object was determined by context (discourse and morphological cues from preceding and following utterances as well as contextual notes taken by the 
TABLE 9. The occurrence of $O A$ in first and second person contexts

\begin{tabular}{lcccr}
\hline & Stage I & Stage 2 & Stage 3 & Stage 4 \\
\hline Utterances with OA & I 5 & I 4 & 84 & 42 \\
Utterances without OA & $5(25 \%)$ & $3($ I $8 \%)$ & $3(4 \%)$ & $\circ$ \\
Total & 20 & I7 & 87 & 42 \\
\hline
\end{tabular}

experimenter). As always, repetitions, unclear cases and utterances containing unintelligible speech were excluded. Of the is 86 transitive and ditransitive utterances, a total of 166 utterances with first or second person objects were identified. These represent obligatory contexts for object agreement. Of these i 66 utterances, a total of I I occurred incorrectly without $\mathrm{OA}$, an error rate of $6.6 \%$. The results are presented by stage in Table 9, showing that at earlier stages the error rate appears higher than the overall error rate.

At first glance it appears as if $\mathrm{OA}$ is omitted at relatively high rates in stages $\mathrm{I}$ and 2 (25 and $\mathrm{I} 8 \%$ respectively), suggesting that, contrary to the results presented so far, OA is only acquired by stage 3 . However, a closer look at the tokens in each stage reveals this not to be the case. The exhaustive list of 5 errors in stage $\mathrm{I}$ and 3 errors in stage 2 are presented in (19):

( I 9)

Stage I :
a. ta tap a
fut - slap - IND
'(I) will slap (you).'
b. ta tun a
fut - pinch - IND
'(I) will pinch (you),
c. ni na chap a
$\mathrm{SA}_{1 \mathrm{~s}}$ - pres - slap - IND
'I am slapping (you).'
Stage 2:

Muso3, age 2;2.0 I

(occurred a total of three times in this file)

Mus 03, age 2;2.0 I
d. ta tap a
fut - slap - IND
'(I) will slap (you).'
e. chap a
slap - IND
'(I will) slap (you).'

Muso3, age 2;2.0 I

Mus I 8 , age $2 ; 8$. I I

f. gong a wewe gong a

Muso9, age 2;4.29

bang - IND you bang - IND

Mus I9, age $2 ; 8.25$

'(I will) bang you, (I will) bang you.' 
There are two noteworthy points here. First, all eight errors come from the same child, and all five errors in stage $\mathrm{I}$ come from the same data point (Muso3, age $=2 ; 2.01$ ). This child does use OA correctly with a first person object both in an earlier session (Muso , age $=2$; 0.16 ) and in later sessions. The second point is that 6 of these 8 errors involve the same verb: chapa, a very common verb meaning 'slap'. I suggest that the high rate of omission of $\mathrm{OA}$ in stages $\mathrm{I}$ and 2 may be related to this particular verb. ${ }^{10}$ If we exclude these tokens from the counts in Table 9 above, the error rates in stages I and 2 fall to $\mathrm{I} 2 \cdot 5 \%(2 / \mathrm{I} 6)$ and $6 \cdot 6 \%$ (I/I 5 ) respectively.

The data presented above show that in the three contexts in which OA is obligatory, children correctly provide OA, suggesting that children respect the Specificity Condition. However, this is not enough to tell us that OA is fully acquired. The children may be overusing OA without knowledge of the conditions under which OA may occur. That is, children may simply be using OA with all verbs, as a filler syllable, of sorts (Peters, 200I), without full knowledge of the precise contexts in which it should occur. Such a 'filler syllable' strategy could result in the apparent overuse of OA; if investigators only look at obligatory contexts, it may appear as if OA is being supplied appropriately.

Before such a strategy may be considered, it is important to note that Swahili children do indeed produce substantial numbers of filler syllables (just like their Sesotho counterparts, Demuth I992a). The distribution of these filler syllables is consistent with the description provided by Peters (200I): they are much more frequent in prefixal positions than suffixal positions, and are usually either nasal or some sort of central vowel, either mid (e.g. schwa) or low (e.g. [a]). Thus because filler syllables are attested in child Swahili, and are often of a phonological shape that overlaps with some OA markers (e.g. $[\mathrm{m}]=3 \mathrm{rd}$ person singular, $[\mathrm{n}]=$ reduced ist person singular, see Table 4), it is possible that a strategy of inserting filler syllables may mask the apparent absence of knowledge of the conditions in which OA may occur.

There are three reasons to reject such a possibility. First, the data in Table 7 show that the overall rate of OA in the various stages is no higher than $16 \%$. If the near-ı 100 rate of $\mathrm{OA}$ in obligatory context were because of a general over-use of OA via a filler-syllable strategy, then we would expect the overall rate of OA to be close to what is observed when the object

[Io] It is at the very least suspicious that $6 / 8$ of these tokens involve the exact same root. There are various possible reasons for this, such as: (i) this is a formulaic, learned

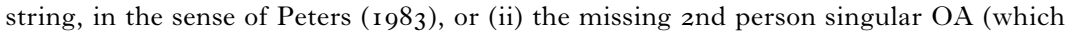
is $[\mathrm{ku}]$ ) combines with the first segment on the root (a voiceless affricate) and is reduced to a voiceless stop. This latter process is fairly common in early Swahili (as it is in other languages). Whatever the underlying cause, the fact that this high rate of error is related to a single verb suggests exclusion of these tokens from the counts of omitted OA. 


\begin{tabular}{lrrr}
\hline & OA & $-\mathrm{OA}$ & \multicolumn{1}{c}{ Total } \\
\hline Transitive & $229(\mathrm{I} 4 \%)$ & $\mathrm{I} 377(86 \%)$ & $\mathrm{I} 605$ \\
Intransitive & $4(0 \cdot 4 \%)$ & $953(99 \cdot 6 \%)$ & 957 \\
\hline
\end{tabular}

is a proper name, a topic or a first/second person referent, contrary to fact. Second, if children are randomly inserting filler syllables in OA position, this should result in apparent agreement errors. However, not a single agreement error involving object agreement occurs in the entire corpus. The third reason is that, as I show in the section below, not only do children provide OA in obligatory contexts, they never provide OA when $\mathrm{OA}$ is prohibited.

\section{$O A$ in transitive and intransitive clauses}

The evidence in the preceding sections shows that children reliably provide $\mathrm{OA}$ in contexts in which it is obligatory, suggesting that Swahili children have acquired OA and the associated Specificity Condition. However, as we noted in the previous section, the same results would obtain if the children overuse $\mathrm{OA}$ in ALL contexts, employing a 'filler syllable' strategy. If children have no knowledge of the contexts in which OA is appropriate, and the strategy they pursue is to simply insert a filler that sounds like the OA morpheme, our investigation of obligatory contexts for OA would produce the same results: OA is appropriately supplied in obligatory contexts. In order to rule this possibility out, we must investigate contexts in which OA should not and cannot occur, to which we now turn.

One context in which OA may never occur is intransitive clauses because of the (logical) absence of an object. If children are randomly inserting OA-like syllables, then we might expect to see some fillers in intransitive contexts. Table Io shows the rate of $\mathrm{OA}$ in transitive contexts and fillers in intransitive contexts. The data show that children only insert fillers in intransitive contexts $0.4 \%$ of the time.

Thus children acquiring Swahili cannot simply be randomly inserting OA-like syllables into their verbs, or else we would expect a higher rate in intransitive contexts. An anonymous reviewer comments that the insertion of any $\mathrm{OA}$ in intransitive clauses suggests a possible lack of knowledge of the contexts in which this morpheme may or may not occur. This is highly doubtful, however, because the rate of $\mathrm{OA}$ in intransitive clauses is so very low : $0.4 \%$. Furthermore, as seen in (20), all four of these tokens involve nasals, which is typical of filler syllables (the syllables are glossed here as FS - filler syllable). The fact that these tokens are consistent with a filler syllable strategy, and that such cases are so rare, suggest that these few 
tokens are phonological fillers and do not constitute evidence against the claim that children have knowledge of the conditions in which OA may and may not occur.

(20) a. hhii ndua ni nani a ta $m$ kuj a? Fauo7, age 2;0.26 this yes copula who $\mathrm{SA}_{3 \mathrm{~s}}-\mathrm{fut}-\mathrm{FS}$ come - IND

'This, (it) is who (that) will come?' $\begin{array}{lllll}\text { b. maha, xxx na } \mathrm{n} & \text { goj } & \mathrm{e} & \text { Mus23, age 2; ro. } 10\end{array}$ '... and (he) should wait.'

c. na ka $\mathrm{m} \quad \mathrm{ku}$ a na

and cont - $\mathrm{OA}_{3 \mathrm{~s}}$ be - IND and

na $\mathrm{i}$ on a Hasor, age 2 ; IO. 3

pres $-\mathrm{OA}_{\text {inanim }}-$ see - IND

'And (he then) was with ... seeing it.'

d. $i \quad n i \quad m$ potez a wapi? Haso3, age 2; I I. I I $\mathrm{SA}_{\text {inanim }}$ - pres - FS lose - IND where

'Where is this lost?'

An anonymous reviewer suggests that a discourse analysis of the 229 tokens of OA in transitive clauses would provide a fuller picture of whether $\mathrm{OA}$ is acquired appropriately or not. However, as argued above, an analysis of a phenomenon such as specificity using naturalistic data is extremely difficult because one never knows what the child's intention is. If OA occurs in a transitive clause in the apparent absence of an antecedent (which therefore fails to establish specificity), it may appear to adults that the child is making an error, but one does not know whether the child in fact intends a specific reading. This is precisely why I limit myself to the three contexts (when the object is a name, topicalized or first/second person): these are the contexts in which $\mathrm{OA}$ is absolutely obligatory because the grammatical conditions require a specific object. Thus, while further analyses of these 229 tokens may be fruitful in some other regard, with respect to the current study I believe it would be inconclusive.

The data presented here show that children: (i) provide OA in obligatory contexts (when the object is a name, topicalized, or refers to a first/second person), and (ii) never use filler syllables that are OA-like in contexts in which OA is not permissible. These two facts hold in all stages of the data, starting with the least mature child at approximately age I; Io. I therefore conclude that $\mathrm{OA}$ and the Specificity Condition are acquired by stage $\mathbf{I}$.

\section{DISCUSSION AND CONCLUSION}

The goal of this study was to investigate the acquisition of an abstract property of language-nominal specificity. Researchers make contrasting 
claims regarding the age at which knowledge of specificity is acquired. Schaeffer (2000) argues that children lack knowledge of specificity at early ages (before $3 ; 0$ ), leading to the omission of determiners in obligatory contexts and the failure to scramble pronouns. Avrutin \& Brun (200I) show that in Russian, children as young as $\mathrm{I} ; 7$ respect the specificity of arguments, and generally correctly place arguments preverbally or postverbally, depending on their specificity. I investigated the acquisition of object agreement in Swahili, which has a bearing on this debate because of the Specificity Condition: object agreement is obligatory if the object is specific, and obligatorily absent when the object is non-specific.

It was found that OA occurs reliably in all three obligatory contexts investigated. Additionally, it was found that OA is never used in contexts in which $\mathrm{OA}$ is prohibited, i.e. in intransitive clauses. The conclusion is that both $\mathrm{OA}$ as well as the associated Specificity Condition are acquired early by Swahili speaking children.

Russian and Swahili are obviously typologically very different languages. The manner in which specificity is expressed in these languages is significantly different - in Russian, specificity is expressed through the placement of arguments in relation to the verb; in Swahili specificity is expressed through the occurrence or non-occurrence of OA on the verb. The fact that children acquiring both these languages show knowledge of the respective grammatical effects of specificity from before 2; 0 leads me to propose that cross-linguistically young children do have knowledge of nominal specificity. ${ }^{11}$

The reasons why Dutch children fail to scramble and fail to provide determiners in obligatory context are left open, but there are some points worth mentioning. The encoding of specificity in Dutch is similar to that of Russian in that it correlates with leftward movement of the NP - an NP that moves to the left must be specific, and thus non-specific NPs may never move leftward. However, there are several additional complications that may contribute to the relatively slow expression of specificity in early Dutch. The first is that the correlation of specific NPs moving leftward only holds in one direction, that is, not all specific NPs move leftward. Thus specific NPs may move leftward, but may also remain in their original positions, while non-specific NPs do not have the option to move.

An additional complication in Dutch (alluded to earlier) is that there is a difference between pronominal NPs and non-pronominal NPs in that the former obligatorily scramble leftward while the latter optionally scramble.

[II] There is mounting evidence that errors of the sort seen in Dutch are far from crosslinguistically attested. Ilic and Deen (2004) show that Serbo-Croatian 3 year old children exhibit knowledge of specificity, and Gavarró (2005) shows that object clitic omission is not homogeneous across languages. 
One further complication is that there are various 'zones' of leftward movement that are governed by various discourse and pragmatic conditions (see Schaeffer, I 997). Thus under certain conditions, a pronoun may move leftward to the beginning portion of the sentence ('zone' $\mathrm{I}$ ), and under other circumstances the pronoun may move leftward to a preverbal position that is not sentence initial ('zone' 2 ), or the pronoun may move leftward to a postverbal position ('zone' 3 ). I suggest therefore that the apparent delay in the overt expression of specificity-related phenomena in Dutch is not related to the absence of knowledge of specificity per se, but rather to the myriad complications that exist in Dutch that combine to create a picture that is far from clear. Schaeffer herself makes precisely this argument in her explanation of why Dutch children show an apparent delay in the expression of specificity in Dutch. Whatever the reason ultimately turns out to be for this delay, what seems clear in light of the Swahili and Russian evidence is that this is something specific to Dutch (and perhaps other closely related languages such as German) and not to an underspecification or delay of a particular semantic feature.

Finally, how do these results fit in to what we know about the acquisition of object agreement in other Bantu languages? We saw earlier that in other Bantu languages OA is omitted in great proportions at early stages, suggesting that $\mathrm{OA}$ has not been acquired. However, the evidence I present here for Swahili suggests otherwise: evidence for the acquisition of OA in Swahili is exhibited by children as young as $\mathrm{I}$; $\mathrm{I}$ O. The absence of OA may very well be an absence in the child's desire/ability to understand what the interlocutor considers specific or not, but when the child intends a specific interpretation, the child is able to express that interpretation using the correct grammatical tools. For those Bantu languages in which OA is related to specificity (as it is in Swahili), I suggest that the omission of OA in child speech may be related to discourse and pragmatic conditions that are as yet unexplored, and not to a particular grammatical deficit.

\section{REFERENCES}

Abbott, B. (2005). Definite and indefinite. In K. Brown (ed.) Encyclopedia of language and linguistics, 2nd ed. New York: Elsevier.

Ashton, E. O. (1947). Swahili Grammar. London: Longmans, Green and Co.

Avrutin, S. \& Brun, D. (200I). The expression of specificity in a language without determiners: evidence from child Russian. In A. H.-J. Do, L. Domínguez \& A. Johansen (eds), The Boston University Conference on Language Development 25 Proceedings. Somerville, MA: Cascadilla Press.

Bhatt, R. \& Anagnostopoulou, E. (1996). Object shift and specificity: evidence from ko-phrases in Hindi. Papers from the Regional Meetings, Chicago Linguistic Society, 1996 32(I), I I-22.

Bloom, P. (2000). How children learn the meanings of words. Cambridge, MA: MIT.

Bottari, P., Cipriani, P. \& Chilosi, A. M. (1993/r 994). Protosyntactic devices in the acquisition of Italian free morphology. Language Acquisition 3(4), 327-69. 
Brown, R. (1973). A first language: the early stages. London: Allen and Unwin.

Carstens, V. (I99I). The morphology and syntax of determiner phrases in Kiswahili. Unpublished doctoral dissertation, UCLA.

Chimombo, M. \& Mtenje, A. (I989). Interaction of tone, syntax and semantics in the acquisition of Chichewa negation. Studies in African Linguistics 2o, 103-50.

Deen, K. U. (2002a). 'The acquisition of Nairobi Swahili : the morphosyntax of inflectional prefixes and subjects'. Unpublished doctoral dissertation, UCLA.

Deen, K. U. (2002b). 'Underspecified verb forms and subject omission in Nairobi Swahili.' In B. Beachley, A. Brown \& F. Conlin (eds), The Boston University Conference on Language Development 27 Proceedings. Somerville, MA: Cascadilla Press.

Deen, K. U. (2003). 'Acquisition of inflectional prefixes in Nairobi Swahili.' Annual Review of Language Acquisition 3, I 39-79.

Deen, K. U. (2005). The Acquisition of Swahili. Amsterdam: John Benjamins.

Demuth, K. ( 984 ). Aspects of Sesotho language acquisition. Bloomington: Indiana University Linguistics Club.

Demuth, K. (1988). Noun classes and agreements in Sesotho acquisition. In M. Barlow \& C. A. Ferguson (eds), Agreements in natural language: approaches, theories and descriptions. Center for the Study of Language and Information: University of Chicago Press.

Demuth, K. (1992a). The acquisition of Sesotho. In Dan I. Slobin (ed.), The crosslinguistic study of language acquisition. Hillsdale, $\mathrm{NJ}$ : Erlbaum.

Demuth, K. (1992b). Accessing functional categories in Sesotho: interactions at the morpho-syntax interface. In J. Meisel (ed.), The acquisition of verb placement : functional categories and $V_{2}$ phenomena in language acquisition. Dordrecht: Kluwer Academic Publishers.

Demuth, K. (I 994). On the underspecification of functional categories in early grammars. In B. Lust, M. Sũner \& J. Whitman (eds), Syntactic theory and first language acquisition: crosslinguistic perspectives. Hillsdale, NJ : Erlbaum.

Diesing, M. (г 992). Indefinites. Cambridge, MA: MIT.

Enç, M. (I991). 'The semantics of specificity.' Linguistic Inquiry 22, I, Winter, I-25.

Fodor, J. \& Sag, I. (I982). Referential and quantificational indefinites. Linguistics and Philosophy 5, 355-98.

Gavarró, A. (2005). Object clitic omission: a crosslinguistic review. Paper presented at the International Association for the Study of Child Language (IASCL), Berlin, Germany, July 2005 .

Heim, I. (1982). The semantics of definite and indefinite noun phrases. Unpublished doctoral dissertation, Amherst, MA: University of Massachusetts.

von Heusinger, K. (2002). Specificity and definiteness in sentence and discourse structure. Fournal of Semantics 19, 245-74.

Hornstein, N. (1984). Logic as grammar. Cambridge, MA: MIT.

Hyams, N. (r 996). The underspecification of functional categories in early grammar. In H. Clahsen (ed.), Generative perspectives on first language acquisition. Amsterdam: John Benjamins.

Ilic, T. \& Deen, K. U. (2004). Object raising and cliticization in Serbo-Croatian child language. In J. van Kampen \& S. Baauw (eds), Proceedings to the 2003 GALA conference. Utrecht, Netherlands: LOT.

Karimi, S. (I 999). A note on parasitic gaps and specificity. Linguistic Inquiry 30, 4, 704-I 3.

Karimi, S. (2003). On object positions, specificity and scrambling in Persian. In S. Karimi (ed.), Word order and scrambling, explaining linguistics. Oxford: Blackwell Publishers.

Kunene, E. (I979). The acquisition of SiSwati as a first language: a morphological study with special reference to noun prefixes, noun classes and some agreement markers. Unpublished doctoral dissertation, UCLA.

MacWhinney, B. (2000). The CHILDES project: tools for analyzing talk, 3rd ed. Mahwah, NJ : Erlbaum.

Mahajan, A. (I992). The specificity condition and the CED. Linguistic Inquiry 23, 3, summer, 5 I0-I6. 
Peters, A. M. (1983). The units of language acquisition. Cambridge: CUP.

Peters, A. M. (200I). Filler syllables: what is their status in emerging grammar? fournal of Child Language 28, 229-42.

Quesada, J. D. (2000). The grammaticalization of specificity (and beyond) in Boruca. International Fournal of American Linguistics 66(4), 549-62 I.

Reinhart, T. (1983). Anaphora and semantic interpretation. London: Croom-Helm, University of Chicago Press.

Schaeffer, J. (I 997). Object scrambling, object (-clitic) placement and nominal specificity in Dutch child language. In E. Hughes, M. Hughes \& A. Greenhill (eds), The Boston University Conference on Language Development $2 I$ Proceedings, 2. Somerville, MA: Cascadilla Press.

Schaeffer, J. (2000). Object scrambling and specificity in Dutch child language. In S. Powers \& C. Hamann (eds), The acquisition of scrambling and cliticization. Studies in theoretical psycholinguistics 26. Dordrecht: Kluwer.

Seidl, A. \& Dimitriadis, A. (1997). The discourse function of object marking in Swahili. Papers from the Regional Meetings, Chicago Linguistic Society, 1997, 33 I, 373-87.

Suzman, S. (1982). Strategies for acquiring Zulu concord. South African Fournal of African Languages 2, 53-67.

Suzman, S. (I99I). Language Acquisition in Zulu. Unpublished doctoral dissertation, University of Witwatersrand.

Tsonope, J. (1987). The acquisition of Setswana noun class and agreement morphology, with special reference to demonstratives and possessives. Unpublished doctoral dissertation, State University of New York, Buffalo.

Valian, V. (I99r). Syntactic subjects in the early speech of American and Italian children. Cognition 40, $2 \mathrm{I}-8 \mathrm{I}$. 